\title{
Can Preoperative Axillary Ultrasound and Biopsy of Suspicious Lymph Nodes Be An Alternative To Sentinel Lymph Node Biopsy in Clinical Node Negative Early Breast Cancer?
}

\author{
İsmail Ozler ${ }^{1}$, Hale Aydin² ${ }^{2}$ Onur Can Guler ${ }^{3}$, Işıl Esen Bostanc1 ${ }^{2}$, Bahar Şahin Güner ${ }^{2}$, \\ Niyazi Karaman ${ }^{3}$, Lütfi Doğan ${ }^{4}$, and Cihangir Özaslan ${ }^{3}$ \\ ${ }^{1}$ Affiliation not available \\ ${ }^{2}$ Radiology Clinics of University of Health Sciences, Ankara Oncology Education and \\ Research Hospital, Ankara, Turkey \\ ${ }^{3}$ General Surgery Clinics of University of Health Sciences, Ankara Oncology Education and \\ Research Hospital, Ankara, Turkey \\ ${ }^{4}$ Dr Abdurrahman Yurtaslan Onkoloji Eğitim ve Araştırma Hastanesi
}

January 7, 2021

\begin{abstract}
Aim: The aim of this study was to assess the efficacy of pre-operative axillary ultrasonography (AUS) and pre-operative axillary fine-needle aspiration biopsy (FNAB) from suspicious lymph nodes in clinically node-negative breast cancer to compare with radiologically positive and sentinel lymph node biopsy (SLNB) positive involvement. Method: Clinically node-negative earlystage breast cancer patients were included in the study. These patients under went pre-operative AUS examination, suspicious lymph nodes were evaluated with FNAB. AUS-FNAB results were compared with those of SLNB or of axillary dissection. Results: Of 181 patients undergoing AUS, 32 were reported to have axillary metastasis, 25 suspicious and 124 benign nodes. The suspicious group underwent FNAB examination and metastasis was found in 9 of them. The sensitivity of AUS-FNAB was found to be $64.06 \%$, specificity $100 \%$, positive predictive value $100 \%$ and negative predictive value (NPV) $83.5 \%$. False negativity rate $(\mathrm{FN})$ of this method was $16,4 \%$. Lymphovascular invasion and tumor size were found statistically significant factors for false negativity. Conclusion:It was concluded that axillary AUS-FNAB with its high NPV, low FN rate, may be a clinical alternative to SLNB for early stage breast cancer patients.
\end{abstract}

\section{Hosted file}

main manuscript.pdf available at https://authorea.com/users/388067/articles/502898-canpreoperative-axillary-ultrasound-and-biopsy-of-suspicious-lymph-nodes-be-an-alternativeto-sentinel-lymph-node-biopsy-in-clinical-node-negative-early-breast-cancer

\section{Hosted file}

figures.pdf available at https://authorea.com/users/388067/articles/502898-can-preoperativeaxillary-ultrasound-and-biopsy-of-suspicious-lymph-nodes-be-an-alternative-to-sentinellymph-node-biopsy-in-clinical-node-negative-early-breast-cancer 